\title{
Article \\ Efficacy of Liquid Soap and Alcohol-Based Hand Sanitisers in Eradicating Viable Conidia of the Mushroom Pathogen Lecanicillium fungicola on Contaminated Hands
}

\author{
Brian McGuinness, Elodie Baqué and Helen Grogan * \\ Horticulture Development Department, Teagasc Food Research Centre, Ashtown, D15 KN3K Dublin, Ireland; \\ brian.mcguinness@teagasc.ie (B.M.); baque.elo@gmail.com (E.B.) \\ * Correspondence: helen.grogan@teagasc.ie
}

check for

updates

Citation: McGuinness, B.; Baqué, E.; Grogan, H. Efficacy of Liquid Soap and Alcohol-Based Hand Sanitisers in Eradicating Viable Conidia of the Mushroom Pathogen Lecanicillium fungicola on Contaminated Hands. Agronomy 2021, 11, 1600. https:// doi.org/10.3390/agronomy11081600

Academic Editors: Jaime Carrasco and Francisco J. Gea

Received: 19 June 2021

Accepted: 2 August 2021

Published: 12 August 2021

Publisher's Note: MDPI stays neutral with regard to jurisdictional claims in published maps and institutional affiliations.

Copyright: (c) 2021 by the authors. Licensee MDPI, Basel, Switzerland. This article is an open access article distributed under the terms and conditions of the Creative Commons Attribution (CC BY) license (https:/ / creativecommons.org/licenses/by/ $4.0 /)$.
Abstract: Lecanicillium fungicola causes dry bubble disease of the white button mushroom and produces masses of sticky conidia. Humans are an important vector in the spread of this disease in mushroom farms. Three hand cleaning treatments (tap water, liquid soap and alcohol-based hand sanitisers (ABHSs)) were evaluated for their effectiveness at eliminating conidia of L. fungicola from a contaminated index finger. The hand sanitisers were highly efficacious in reducing the number of viable L. fungicola conidia on contaminated fingertips, although some variability was encountered. The tap water and liquid soap treatments had little effect. An in vitro test confirmed that the $\log _{10}$ reduction in viable conidia after 1 min exposure to the different treatments was $\leq 1$ for tap water and soap and $>4$ for the ABHSs, which is similar to what is achieved in the medical care field for many bacteria and viruses. Thus, regular use of ABHSs by staff on mushroom farms may help to reduce the incidence of dry bubble disease. Their use could also be beneficial in other areas of intensive horticulture or agriculture where human hands are known to transmit plant pathogens to uninfected plants.

Keywords: dry bubble disease control; hand hygiene; spore dispersal; sticky spores; integrated pest management (IPM)

\section{Introduction}

Lecanicillium fungicola (Pruess) Zare and Gams (synonym: Verticillium fungicola (Pruess) Hassebrauk) is one of the most important pathogens of the commercially produced mushroom Agaricus bisporus (Lange) Imbach [1]. The pathogen is found worldwide, wherever A. bisporus is grown, and causes the disease known as "dry bubble". It can have a devastating effect on mushroom production levels, and it is estimated to cause annual losses of $2-4 \%$ of total revenue for mushroom growers. Infected mushrooms eventually produce masses of thin-walled Lecanicillium conidia, held together in clusters with sticky mucilage, and this mucilage enables them to become attached to-and transported by-flies, crop debris, dust, mites, and people. Conidia will also be dispersed by water-splash during crop watering [1,2]. Primary infections on farms are usually associated with the casing soil and equipment becoming contaminated with infected soil or debris, infected mushroom flies or via the infected footwear, clothing or hands of personnel involved in the casing operation $[1,3,4]$. Primary infections can be reduced by the implementation of good hygiene practices and good farm management $[5,6]$. Once a primary infection starts on a farm, the disease can be spread further by water-splash, the movement of contaminated flies within and between crops, and the movement of infected debris, dust and personnel around the farm. All of these activities will build up inoculum reservoirs on the farm that can lead to further primary infections in new crops. Piasecka et al. [7] surveyed mushroom farms for reservoirs of L. fungicola conidia and detected viable L. fungicola in samples taken from mushroom picking accessories/equipment (23-27\% of samples), growing room floors 
$(35 \%)$, door handles $(16 \%)$ and canteen areas $(13 \%)$, indicating how the pathogen can be easily spread by personnel who are in close contact with infected crops. Once the conidia have been spread onto door handles, floors and canteen areas, then all farm personnel can become contaminated and facilitate the further spread of the disease around the farm (Figure 1). Hands contaminated by L. fungicola conidia are not easy to clean, even using soap and hot water [1], as the sticky mucilage surrounding the conidia enables them to adhere strongly to the skin. Frequent hand washing using efficacious products and techniques is essential to reduce the potential spread of L. fungicola on commercial farms. Although disposable gloves are used when harvesting mushrooms, harvesters can very easily contaminate their bare hands when disease levels on a farm are high.

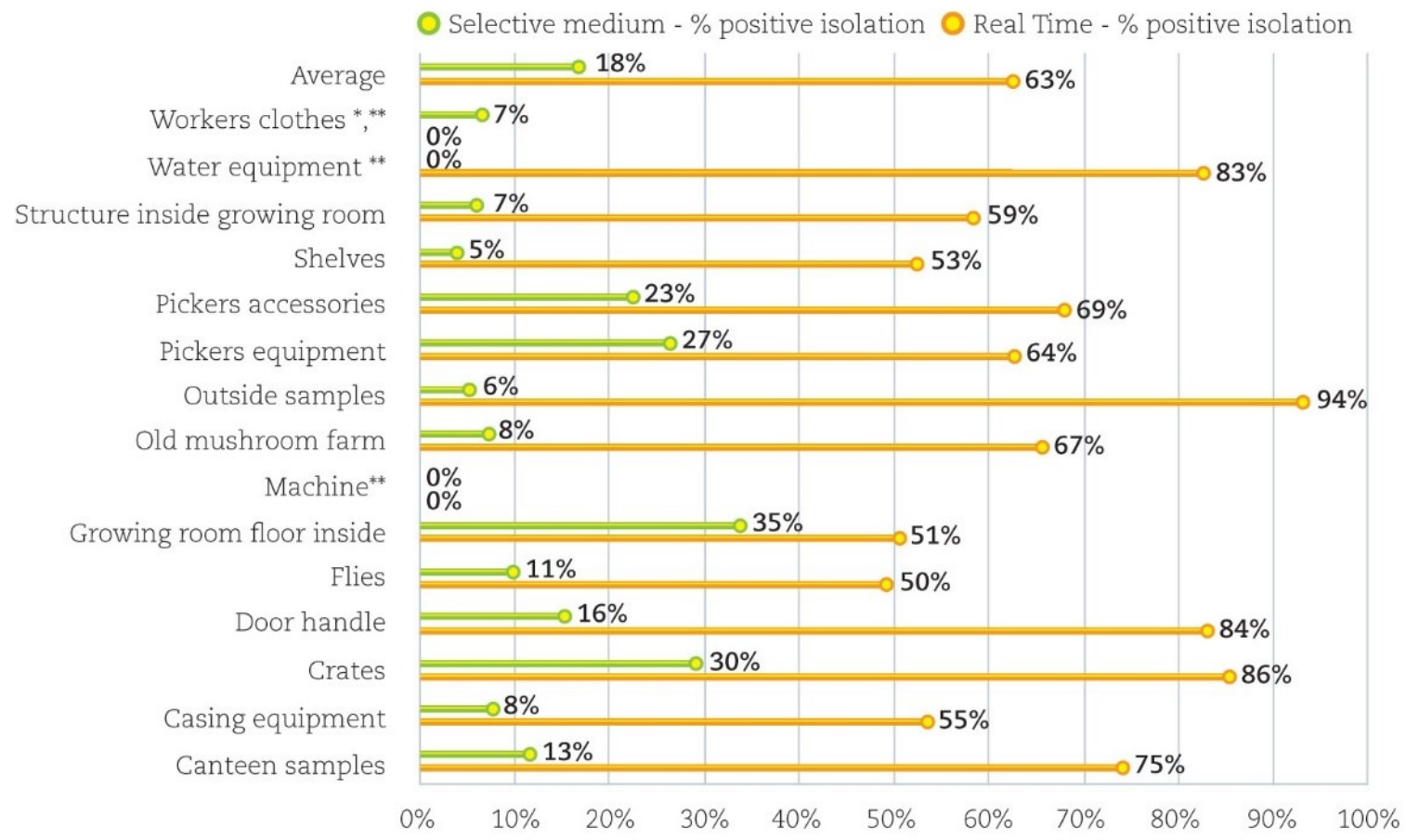

Figure 1. Detection of L. fungicola in samples taken from various locations on mushroom farms and tested using selective media (upper green bar) or real time PCR (lower orange bar) (438 samples in total) ${ }^{*}$ only selective medium tested; ${ }^{* *}$ not enough samples for comparison. From Piasecka et al. [7].

In recent years, alcohol-based hand sanitisers (ABHSs) have been used in the health sector to combat the transmission and spread of infectious bacteria and viruses in hospital and health care environments. The antimicrobial activity of solutions containing $60-95 \%$ alcohol is due to its ability to penetrate into cells and denature essential cell proteins [8]. Efficacy varies depending on the type of organisms targeted. Boyce and Pittet [8] reported that alcohols have excellent germicidal activity against Gram-positive and Gramnegative vegetative bacteria in vitro and in vivo, as well as against various fungi in vitro. Grayson et al. [9] found that soap and water and ABHSs were both effective at reducing live H1N1 virus numbers on human hands, but that soap and water hand washing was statistically more effective. Jabbar et al. [10] reported that hand washing with soap and water is more effective than ABHSs at removing the resilient spores of the bacterium Clostridium difficile from hands. More recently, Singh et al. [11] reviewed the literature on hand sanitisers and hand washing in relation to COVID-19 hand hygiene and found that ABHSs were less effective if hands were greasy or soiled and that hand washing with soap and water was more efficacious and convenient. At a practical level, Leslie et al. [12] found that two commercial ABHSs gave a $\log _{10}$ reduction of $>3$ for SARS-CoV-2. Few studies have been performed with ABHSs and fungi, however; Fendler and Groziak [13] reported a $\log _{10}$ reduction of $>4$ in vitro for six out of seven fungal species tested. The fact that good 
antifungal activity has been demonstrated in vitro for ABHSs suggests they may be useful for reducing L. fungicola conidia from the hands of mushroom personnel. The purpose of this study was to assess the effectiveness of different hand cleaning treatments on the survival of L. fungicola conidia both in vitro and in vivo.

\section{Materials and Methods}

\subsection{Fungal Culture}

Lecanicillium fungicola culture 17A, originally isolated from an infected A. bisporus mushroom in 2008, was sub-cultured on potato dextrose agar (PDA) containing streptomycin sulphate at $100 \mathrm{ppm}(\mathrm{PDA}+\mathrm{S})$ in $90 \mathrm{~mm}$ Petri dishes. Cultures were incubated at $25^{\circ} \mathrm{C}$ for 14 days, by which time they were producing abundant conidia and were ready for use in tests. PDA $+S$ or PDA was used for fingertip imprints, as described in Sections 2.3 and 2.5 below.

\subsection{Hand Cleaning Products}

Two soap-based and two alcohol-based hand cleaning gel products (Table 1) were tested for their efficacy in inactivating L. fungicola conidia in vitro and in vivo.

Table 1. Test products and their composition of listed ingredients.

\begin{tabular}{|c|c|}
\hline Test Product & Product Composition \\
\hline $\begin{array}{c}\text { Liquid soap } 1 \\
\text { (Ultimatic N99930, Georgia-Pacific, Nokia, Finland } \\
\text { (Discontinued, similar alternatives at https:/ / www.gppro.com/ } \\
\text { accessed on } 3 \text { August 2021) }\end{array}$ & $\begin{array}{l}\text { Aqua, Sodium Laureth Sulfate, PEG-4-Rapeseedamide, } \\
\text { Cocamidopropyl Betaine, MEA-Lauryl Sulphate, Sodium } \\
\text { Chloride, Propylene Glycol, Glycerine, 2-Phenoxyethanol, } \\
\text { Sodium Benzoate, Glycol Stearate, Parfum, Dehydroacetic Acid, } \\
\text { Cocamide MEA, Cocamide DEA, Octoxyglycerin, Citric Acid. } \\
\text { Aqua, Sodium Laureth Sulfate, Cocamidopropyl Betaine, Lactic }\end{array}$ \\
\hline $\begin{array}{l}\text { Liquid soap } 2^{1} \\
\text { (Carex Bacteria Protect with Zinc, Cussons, Manchester, UK } \\
\text { https:// carex.co.uk/ accessed on } 3 \text { August 2021) }\end{array}$ & $\begin{array}{l}\text { Acid, Sodium Chloride, Glycerin, Polyquaternium-7, Parfum, } \\
\text { Zinc Coceth Sulfate, Sodium Benzoate, Styrene/Acrylates } \\
\text { Copolymer, Tetrasodium Glutamate Diacetate, Benzotriazol } \\
\text { Dodecyl p-Cresol, Polysorbate 20, Citronellol, Coumarin, Hexyl } \\
\text { Cinnamal, Butylphenyl Methypropional, CI 42090. }\end{array}$ \\
\hline $\begin{array}{l}\text { Alcohol-based hand sanitiser gel } 1 \text { (SteriClean, Advanced } \\
\text { Technology Products, Limerick, Ireland, https:/ / www.atp.ie/ } \\
\text { accessed on } 3 \text { August 2021) }\end{array}$ & $\begin{array}{l}60-70 \% \text { ethanol, } 1-10 \% \text { glycerine, } 0-0.5 \% \text { cyclohexane, } 0-0.5 \% \\
\text { acrylic acid copolymer, } 0-0.5 \% \text { ethylacetate. }\end{array}$ \\
\hline $\begin{array}{l}\text { Alcohol-based hand sanitiser gel } 2^{1} \text { (HypaClean, Safety First } \\
\text { Aid Group, London, UK, https: / / www.safetyfirstaid.co.uk// } \\
\text { accessed on } 3 \text { August 2021) }\end{array}$ & $\begin{array}{l}70 \% \text { denaturated ethanol, Aqua, Glycerin, Lauryl, } \\
\text { Aminopropylglycine, Chlorhexidine Digluconate. }\end{array}$ \\
\hline
\end{tabular}

${ }^{1}$ The composition of the currently available product is similar, but slightly different, to that used in the study.

\subsection{Preliminary In Vivo Assessment of Hand Cleaning Treatments on the Survival and Transmission of L. fungicola}

At the start of the experiment, hands were washed for 1 min using liquid soap 1 according to current World Health Organisation (WHO) guidelines [14], and dried using a clean paper towel. Hands were disinfected with approx. $3 \mathrm{~mL}$ of a $70 \%$ ethanol solution until dry to ensure initial complete hand disinfection. This is an older method for surgical hand preparation [15] and, given the nature of the experimental work being undertaken, it was used rather than the WHO-recommended alcohol hand rub treatment. The tip of the washed and disinfected right index finger was then imprinted onto a PDA + S Petri dish in ten separate locations (negative control). The same finger was then used to make direct contact with a sporulating culture of L. fungicola for $1 \mathrm{~s}$ and then immediately imprinted, with no hand washing, onto 10 PDA + S Petri dishes, with ten sequential fingerprints imprinted on each Petri dish, giving 100 consecutive fingertip imprints (positive control) (Figure 2). The hands were then washed and disinfected again, as described for the negative control, and a further negative control plate was taken before proceeding with the experimental treatments. The temperature of the water was approximately $30{ }^{\circ} \mathrm{C}$. 


\section{L. fungicola culture}

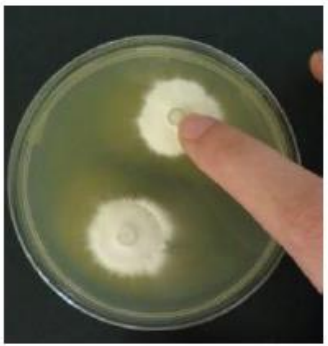

\section{Fingertip imprint}

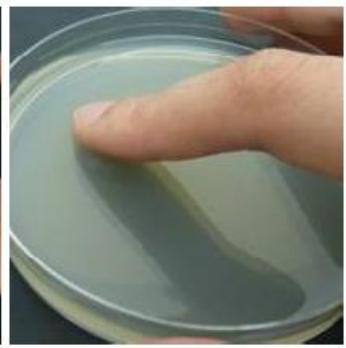

Positive control imprint no.

$1-10$

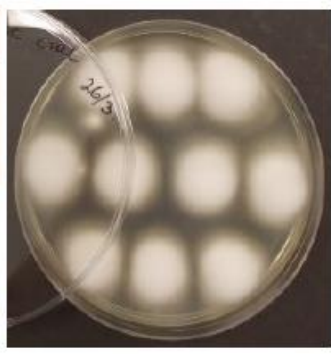

91-10

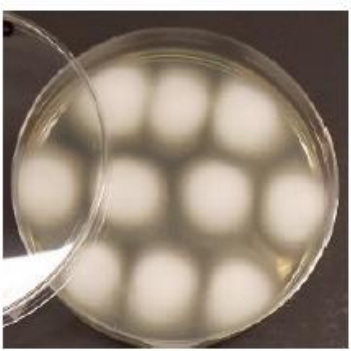

Negative control imprint No. 1-10

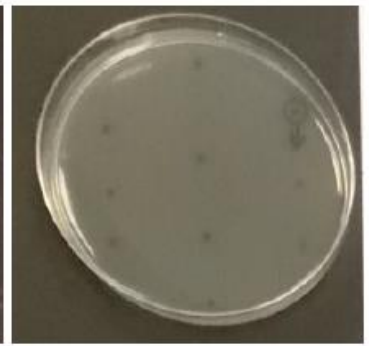

Figure 2. Sequential fingertip imprints on PDA immediately following contamination with L. fungicola (positive control) (imprint numbers 1-10 and 91-100) and after disinfection according to WHO guidelines (negative control) (imprint numbers 1-10).

Hand cleaning treatments consisted of: (a) tap water only, (b) tap water with liquid soap 1; (c) tap water with liquid soap 2; (d) ABHS gel 1 and (e) ABHS gel 2 (Table 1). The quantity of soap and hand gel dispensed was approximately $1.5 \mathrm{~mL}$. Hand cleaning with tap water only was performed for $30 \mathrm{~s}$; hand cleaning with the soap and ABHS gel products was performed for 10, 20 and $30 \mathrm{~s}$. The temperature of the water was approximately $30^{\circ} \mathrm{C}$. WHO guidelines for hand cleaning were followed as far as possible within the time constraints [14]. Clean paper towels were used to pat the hands dry after all cleaning treatments, including after the ABHS treatments, as hands were sometimes still 'wet'. After hand disinfection and before each hand cleaning treatment, the index finger was impressed onto a sporulating culture of L. fungicola. Hands were then subjected to the cleaning treatment and the index finger was immediately imprinted 100 times onto PDA + S Petri dishes, as described above. Before starting the next treatment, the hands were again washed and disinfected, as described for the negative control, and a control fingerprint plate was taken to ensure that there was no cross contamination between treatments. All imprint plates were sealed with parafilm and incubated at $25^{\circ} \mathrm{C}$ for up to 10 days, by which time any viable L. fungicola conidia had germinated to produce a small white colony. The experiment was repeated twice for liquid soap 1, ABHS gel 1 and ABHS gel 2, and once for tap water and liquid soap 2. Imprint plates were photographed and the number of fingertip imprints out of 100 that were positive for L. fungicola was counted.

\subsection{In Vitro Assessment of Antifungal Activity of Hand Cleaning Products against L. fungicola}

A modified method, based on the European Standard test method for chemical disinfectants and antiseptics, prEN 12054 [16] was used to test the in vitro sensitivity of L. fungicola conidia to the two soaps and two ABHSs being evaluated. In summary, sporulating cultures of $L$. fungicola were washed with sterile water to harvest the conidia. The resulting conidial suspension was adjusted with sterile water to give in the region of $1 \times 10^{6}$ conidia $\mathrm{mL}^{-1}$. The two ABHS gels were used undiluted and the handwash soap products were prepared as a $55 \%(v / v)$ dilution in tap water. A $1 \mathrm{~mL}$ aliquot of the L. fungicola conidia suspension was added to $9 \mathrm{~mL}$ of each test product in sterile $50 \mathrm{~mL}$ plastic tubes. Tap water was used as a negative control. After $1 \mathrm{~min}$ contact time, a 1:10 dilution series to $10^{-1}$ was prepared using a neutralising solution consisting of $0.0025 \mathrm{~mol} \mathrm{~L}^{-1}$ phosphate buffer containing: polysorbate $80,30 \mathrm{~g} \mathrm{~L}^{-1}$; L-histidine, $1 \mathrm{~g} \mathrm{~L}^{-1}$; lecithin, $3 \mathrm{~g} \mathrm{~L}^{-1}$; and sodium thiosulphate, $5 \mathrm{~g} \mathrm{~L}^{-1}$. A $100 \mu \mathrm{L}$ aliquot from each serial dilution was spread onto PDA $+\mathrm{S}$ Petri dishes and incubated at $25^{\circ} \mathrm{C}$ for 3 days. The number of viable conidia was counted and the $\log _{10}$ reduction was calculated as follows: $\log _{10}$ (initial count at Time $\left._{\text {zero }}\right)-\log _{10}($ count at Time $1 \mathrm{~min})=\log _{10}$ reduction. 


\subsection{Effect of Two ABHS Gels on the Survival of L. fungicola Conidia on the Hands of Multiple Subjects}

Five adult subjects were invited to participate in this experiment to test the efficacy of ABHS gels 1 and 2 at two dose rates, 1.5 and $3 \mathrm{~mL}$, against $L$. fungicola conidia. Prior to each test, participants washed their hands with soap and water for $1 \mathrm{~min}$ at $30^{\circ} \mathrm{C}$. They then used the reference hand disinfection procedure for surgical hand preparation outlined in CEN standard: EN 12791 [16,17], which consists of rubbing hands with $60 \%$ propyl for $3 \mathrm{~min}$, using as many $3 \mathrm{~mL}$ quantities as required to keep hands moist for $3 \mathrm{~min}$, then allowing them to dry naturally. Ten index fingertip imprints were made onto PDA as a negative control. Participants contaminated their index fingertip with L. fungicola conidia as described earlier, then performed one of the hand cleaning treatments being tested, allowing their hands to dry naturally and then proceeding to make 10 consecutive fingertip imprints on each of 10 PDA Petri dishes. Hands were subsequently washed and disinfected again, as described above, before moving on to the next treatment. All fingertip imprint Petri dishes were incubated for 3 days at $25^{\circ} \mathrm{C}$ and results recorded.

\section{Results}

Viable L. fungicola conidia were present on 100 fingertip imprints for the positive control treatments when either no hand cleaning treatment was conducted or following hand washing in tap water only (30 s) (Figures 2 and 3). After $10 \mathrm{~s}$ of hand washing, viable conidia were still present on 100 fingertip imprints with both liquid soap products, and more than 50 fingertip imprints on average over two experiments with both ABHSs (Figures 4 and 5). Liquid soap 2 was marginally more effective after 20 or $30 \mathrm{~s}$ of hand washing, with fewer L. fungicola-contaminated fingertip imprints and fewer colonies per imprint after 91-100 impressions, while ABHS gel 1 was much more effective than gel 2 over two experiments (Figure 5).

\section{Fingertip imprints:}
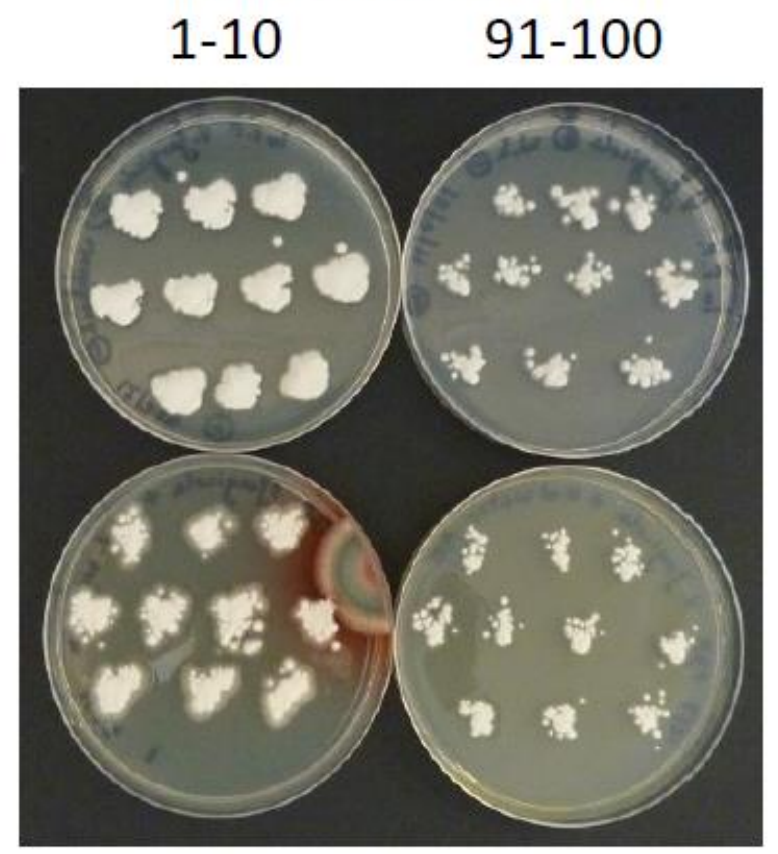

Figure 3. Sequential fingertip imprints (numbers 1-10 and 91-100) of L. fungicola contaminated fingertips: Top: positive control; Bottom: hands washed in tap water only for $30 \mathrm{~s}$. 


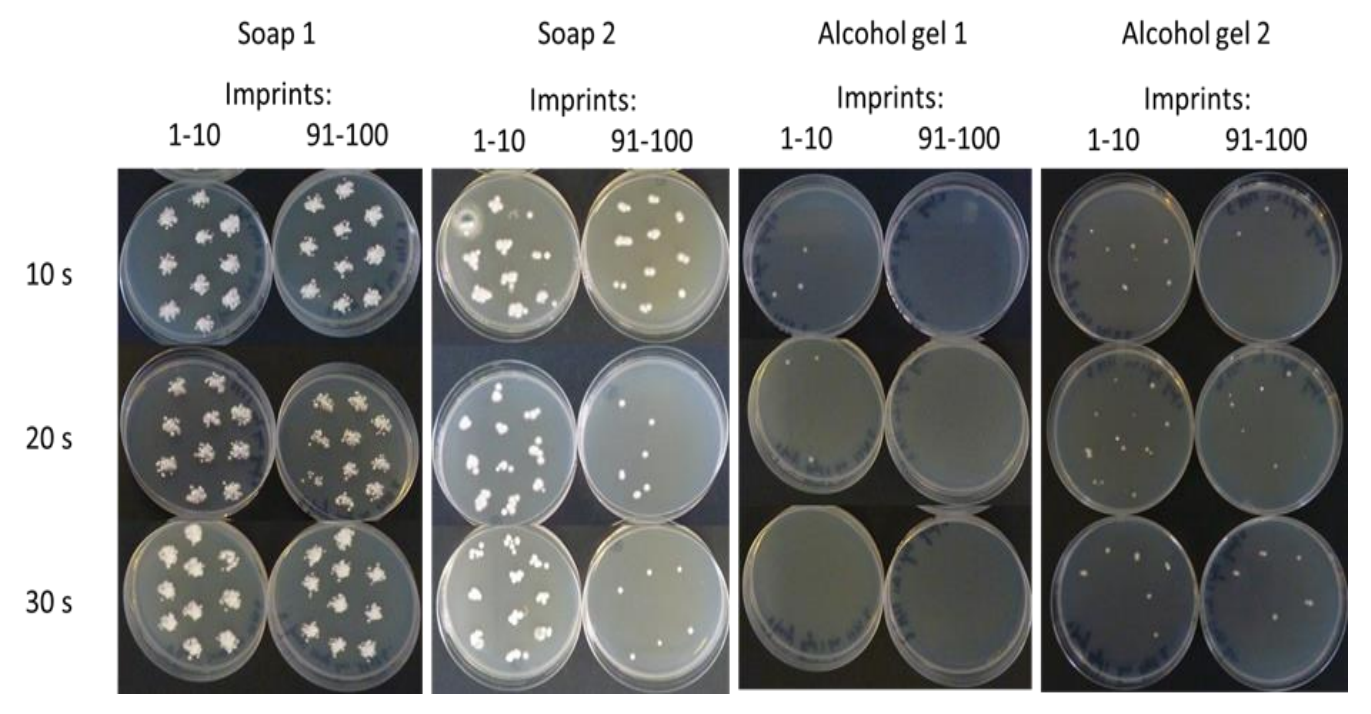

Figure 4. Sequential fingertip imprints of L. fungicola-contaminated fingertips for four products following treatment times of 10,20 or $30 \mathrm{~s}$. Results given for imprints $1-10$ and $91-100$ for each treatment combination from Experiment 2.

\section{L. fungicola-contaminated fingertip imprints}

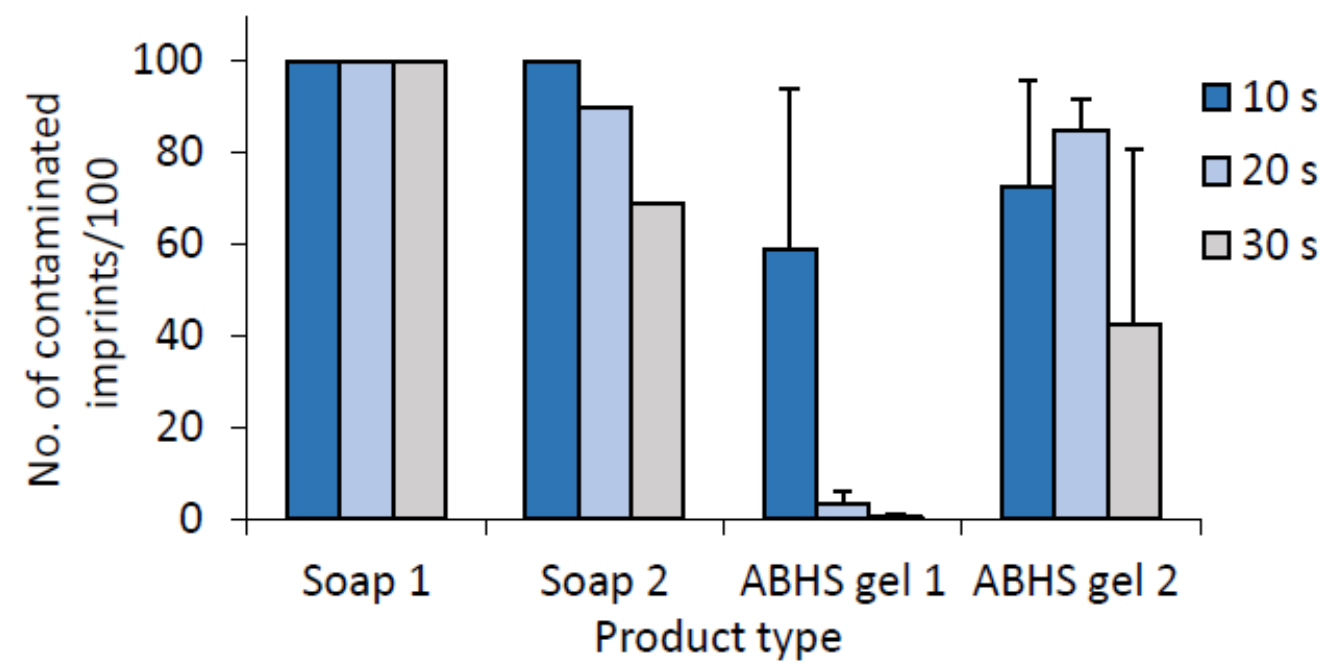

Figure 5. Number of fingertip imprints out of a 100 producing viable L. fungicola colonies after hand cleaning with four products and for three hand-cleaning duration times (10, 20 or $30 \mathrm{~s}$ ). Data are means + SE of two replicate experiments, Soap 2 data for one experiment only.

The two ABHS products were more effective than the two soaps at reducing the number and intensity of contaminated fingerprints after 100 imprints, across all time durations, but there was some variation in the results across the two experiments (Figures 4 and 5). ABHS gel 1 was consistently more effective than gel 2 in reducing both the number of contaminated fingerprints and the number of colonies per imprint, especially after a $30 \mathrm{~s}$ cleaning duration.

The quantitative in vitro test recorded a $\log _{10}$ reduction in L. fungicola viability of $>4$ for both ABHS gel products after 1 min exposure compared to a $\log _{10}$ reduction of $<1$ for the two soap products (Table 2). 
Table 2. Percent viability and $\log _{10}$ reduction of L. fungicola conidia after 1 min exposure to different hand cleaning products.

\begin{tabular}{|c|c|c|c|c|}
\hline Test Product & & L. fungicola CFUs/mL & & $\begin{array}{c}\% \text { Viability } \\
\text { after Treatment } \\
\text { (Log } 10 \text { Reduction) }\end{array}$ \\
\hline & $\begin{array}{l}\text { L. fungicola } \\
\text { conidial } \\
\text { suspension }\end{array}$ & $\begin{array}{c}\text { Test Product solution } \\
(1: 10) \\
\text { Time }_{\text {zero }}\end{array}$ & $\begin{array}{c}\text { Test Product } \\
\text { solution }(1: 10) \\
\text { Time } 1 \mathrm{~min}\end{array}$ & \\
\hline Tap Water Control & $1.4 \times 10^{6}$ & $\begin{array}{c}1.4 \times 10^{5} \\
\left(\log _{10}=5.146\right)\end{array}$ & $\begin{array}{c}1.4 \times 10^{5} \\
\left(\log _{10}=5.146\right)\end{array}$ & $\begin{array}{c}100 \% \\
(0)\end{array}$ \\
\hline Soap 1 & $1.4 \times 10^{6}$ & $\begin{array}{c}1.4 \times 10^{5} \\
\left(\log _{10}=5.146\right)\end{array}$ & $\begin{array}{c}1.3 \times 10^{5} \\
\left(\log _{10}=5.114\right)\end{array}$ & $\begin{array}{c}93 \% \\
\left(<1 \log _{10}\right)\end{array}$ \\
\hline Soap 2 & $1.4 \times 10^{6}$ & $\begin{array}{c}1.4 \times 10^{5} \\
\left(\log _{10}=5.146\right)\end{array}$ & $\begin{array}{c}1.0 \times 10^{5} \\
\left(\log _{10}=5\right)\end{array}$ & $\begin{array}{c}71 \% \\
\left(<1 \log _{10}\right)\end{array}$ \\
\hline ABHS gel 1 & $1.4 \times 10^{6}$ & $\begin{array}{c}1.4 \times 10^{5} \\
\left(\log _{10}=5.146\right)\end{array}$ & $\begin{array}{l}\leq 1.0 \times 10^{1} \\
\left(\log _{10}=1\right)\end{array}$ & $\begin{array}{c}<0.01 \% \\
\left(>4 \log _{10}\right)\end{array}$ \\
\hline ABHS gel 2 & $1.4 \times 10^{6}$ & $\begin{array}{c}1.4 \times 10^{5} \\
\left(\log _{10}=5.146\right)\end{array}$ & $\begin{array}{l}\leq 1.0 \times 10^{1} \\
\left(\log _{10}=1\right)\end{array}$ & $\begin{array}{c}<0.01 \% \\
\left(>4 \log _{10}\right)\end{array}$ \\
\hline
\end{tabular}

The results from multiple subjects indicate that the majority of L. fungicola conidia did not persist on hands that were cleaned with a single $1.5 \mathrm{~mL}$ dose of ABHS gel and allowed to dry naturally, and none persisted when a $3 \mathrm{~mL}$ dose was used (Table 3). Hand size and temperature differed between subjects and the time taken for hands to dry naturally varied between 25 and $58 \mathrm{~s}$ for the 1.5 dose and between 59 and $187 \mathrm{~s}$ for the $3 \mathrm{~mL}$ dose. ABHS gel 1 was marginally better than ABHS gel 2 at the $1.5 \mathrm{~mL}$ dose.

Table 3. Number of fingertip imprints (out of 100) contaminated with L. fungicola conidia for five subjects after hand cleaning treatments with a single $(1.5 \mathrm{~mL})$ or double $(3 \mathrm{~mL})$ dose of two ABHS gels.

\begin{tabular}{|c|c|c|c|c|c|c|}
\hline \multirow[t]{3}{*}{ Subject } & \multirow[t]{3}{*}{$\begin{array}{l}\text { Hand Size } \\
\left(\mathrm{cm}^{2} \text { approx }\right)\end{array}$} & \multirow[t]{3}{*}{ Hand Temp. ${ }^{\circ} \mathrm{C}$} & \multicolumn{4}{|c|}{$\begin{array}{l}\text { Number of Fingertip Imprints out of } 100 \\
\text { with L. fungicola }\end{array}$} \\
\hline & & & \multicolumn{2}{|c|}{ ABHS gel 1} & \multicolumn{2}{|c|}{ ABHS gel 2} \\
\hline & & & $1.5 \mathrm{~mL}$ & $3.0 \mathrm{~mL}$ & $1.5 \mathrm{~mL}$ & $3.0 \mathrm{~mL}$ \\
\hline 1 (female) & -1 & - & 0 & 0 & 3 & 0 \\
\hline 2 (female) & 152 & 27 & 0 & 0 & 0 & 0 \\
\hline 3 (male) & 203 & 32 & 1 & 0 & 1 & 0 \\
\hline 4 (female) & 143 & 21 & 0 & 0 & 1 & 0 \\
\hline 5 (male) & 211 & 32 & 10 & 0 & 81 & 0 \\
\hline
\end{tabular}

${ }^{1}$ No hand data for this subject.

\section{Discussion}

Good hand hygiene is an important aspect in the control of certain human diseases caused by bacteria and viruses, which has been dramatically highlighted in recent times by the worldwide battle to control COVID-19. The advice to wash and disinfect hands regularly is also appropriate for many food businesses, including intensive horticulture production facilities where large numbers of people may be working in close proximity to each other and where the opportunity for cross contamination of shared areas and equipment is high. In the mushroom sector, we have been aware for some time that the sticky conidia of the mushroom pathogen Lecanillium fungicola can be transmitted on hands [1], and a suggestion by a consultant led us to conduct this research on evaluating hand cleaning methods for hands that may be contaminated with the pathogen. The results indicate that washing hands in soap and water was ineffective, while ABHS products were very effective.

The results for soap products indicate that there was minimal eradication of L. fungicola conidia after hand washing for up to $30 \mathrm{~s}$. These results were confirmed in the in vitro test, where conidial viability was reduced to 93 and $71 \%$ for liquid soap 1, and liquid 
soap 2, respectively (Table 2). This level of reduction would be virtually ineffective with respect to eliminating L. fungicola contamination on mushroom farms, as there would still be a high load of conidia on contaminated hands after washing that would facilitate the spread of L. fungicola around the farm, contaminating any surfaces that individuals came in contact with, including equipment, door handles, canteen areas and washrooms. Hand washing with soap is known to be very effective in eliminating certain human viruses and bacteria [9-12], so it is still an important aspect of hand hygiene in workplaces.

The results for the ABHS products indicate that there is a very significant reduction in the number of viable L. fungicola conidia remaining on contaminated fingertips following their use, compared to liquid soaps or tap water, offering excellent potential to reduce L. fungicola contamination loads on mushroom farms. The in vitro results also confirmed a $\log _{10}$ reduction of $>4$, providing good confidence in the ability of the products to kill the conidia. This level of pathogen reduction with ABHSs is in line with the results for similar experiments with bacteria and viruses in the medical health care field [8]. ABHSs are now considered to be the hand cleaning method of choice for patient safety in hospitals and health care facilities [14]; however, they are not effective in killing some endosporeforming bacteria such as Clostridium difficile, where soap and water is the preferred means of hand washing.

During the course of the initial tests, there was variability in the results for the two ABHS gels tested between two separate initial experiments. In Experiment 1, the fingertip imprints after $10 \mathrm{~s}$ of treatment were more highly loaded with viable conidia compared with experiment 2. Additionally, in experiment 2, there was no great difference between the different treatment times for gel 2 , compared to experiment 1 . This highlights a recognised problem with qualitative methods of evaluating the in vivo efficacy of antiseptic handwash and handrub products such as the fingerprint imprint method [17]. In the case of our study, the confounding results may be due to many factors including: (a) inconsistencies in the number of conidia adhering to the fingertip after each test contact; (b) inconsistencies in the hand rubbing technique used from one test to the next and (c) greater or lesser disaggregation of conidia on the fingertip from one test to the next. During the course of the initial experiments, hands were patted dry with paper towels after each treatment as hands were still quite wet after the 10, 20 and $30 \mathrm{~s}$ time duration, and this may have removed, spread and/or dislodged conidia.

A clearer idea of the potential for the ABHS gels for use on mushroom farms is given by the results for the small group of subjects tested in the study. The five participants followed a specific hand cleaning protocol where hands were rubbed together with either a 1.5 (standard) or $3 \mathrm{~mL}$ dose of the ABHSs for as long as needed to disperse the product on the hands, which were then left to air dry. The results were very promising, with the majority of L. fungicola conidia not persisting on hands that were cleaned with a single $1.5 \mathrm{~mL}$ dose of ABHS gel and none persisting when a $3 \mathrm{~mL}$ dose was used (Table 3). ABHS gel 1 was marginally better than ABHS gel 2 at the $1.5 \mathrm{~mL}$ dose, but both performed extremely well, especially compared to the results for gel 2 in the initial experiments.

It was interesting to note that the time taken for hands to dry varied between participants but for the $1.5 \mathrm{~mL}$ dose it was always $\geq 25 \mathrm{~s}$, meaning the results could be compared with the 20-30 s treatments in the initial experiments. Although the sample size was small, at 5 subjects, the results show that there was variability from person to person in terms of results, but also in terms of size and temperature of the person's hands, with the small cold hands of one participant taking longer to dry (58 s) compared with the large warm hands of another participant (25 s). For the $3 \mathrm{~mL}$ dose, both application and drying were more problematic, as subjects said the volume used was too much to hold comfortably, especially in smaller hands, and it took 59-187 s to dry. The results suggest that for most people, the $1.5 \mathrm{~mL}$ dose is almost $100 \%$ effective, but for those with larger hands, a larger dose may be required to ensure good hand coverage and efficacy.

Many plant pathogens are dispersed by sticky propagules. In intensive horticulture, workers may be in close contact with crops at several different stages of growth. They may 
be working in close proximity to others during plant propagation or crop set-up stages, where plants should be disease-free. Such proximity of workers increases the likelihood for human transmission between diseased and non-diseased plants to occur and highlights the need for strict attention to disease-control strategies and management. For example, the tobacco mosaic virus, the fireblight bacterium Erwinia amylovora and the cocoa pod rot pathogen Phytophthora palmivora are easily transmitted from diseased to healthy plants on the hands of farm workers or on pruning tools [18]. Good hand hygiene is a key element in minimising the spread of pathogen inoculum around facilities.

Since this work was completed, the majority of mushroom farms in Ireland have installed hand sanitiser stations outside growing rooms and around the farm. Recent anecdotal feedback from some growers has indicated that disease levels on the farms have reduced since the implementation of strict hand hygiene and other disinfection measures on farms to minimise the potential spread of COVID-19. As a result, growers and staff have a better understanding of how mushroom diseases can be transmitted on farms, and how good hand hygiene is an important aspect in their control. The practice of using ABHSs on mushroom farms makes a significant contribution to an effective integrated pest management (IPM) strategy, as it aims to reduce the spread of a pathogen on the farm, thereby reducing the potential for disease outbreaks to occur and the need for chemical control measures to be used.

\section{Conclusions}

In conclusion, the use of ABHS gel products for hand disinfection purposes has been shown to have potential as a useful hand-cleaning procedure on mushroom farms with dry bubble disease. If used routinely when entering and leaving growing rooms, and in washrooms, canteens, and key target areas and areas of high human activity, it should reduce the level of background contamination of L. fungicola, one of the most persistent fungal pathogens of the commercial mushroom, A. bisporus. There is potential to use ABHSs in other areas of horticulture and agriculture where humans are known to be an important vector of disease.

Author Contributions: Conceptualization, H.G.; methodology, H.G., B.M. and E.B.; investigation, B.M. and E.B.; writing—original draft preparation, H.G.; writing—review and editing, H.G., B.M. and E.B. All authors have read and agreed to the published version of the manuscript.

Funding: This research was funded by Teagasc.

Institutional Review Board Statement: The hand wash trials were conducted in accordance with WHO Guidelines on Hand Hygiene in Health Care $[14,15,17]$ and are in accordance with the guidelines for ethical and professional practices for the sensory analysis of food as set out by the Institute of Food Science and Technology.

Informed Consent Statement: Informed consent was obtained from all participants involved in the study.

Data Availability Statement: The data presented in this study is available from the corresponding author.

Acknowledgments: Elodie Baqué was on six months work experience from École Nationale Supérieure d'Agronomie et des Industries Alimentaires (ENSAIA), Nancy, France as part of her studies for an Engineer degree in Agronomy (Diplôme d'Ingénieur Agronome). The authors would like to thank Dermot $\mathrm{O}^{\prime}$ Morchoe, Mushroom Consultant, for suggesting that alcohol hand gels could be useful in the management of dry bubble disease. We thank the people who agreed to participate in the study.

Conflicts of Interest: The authors declare no conflict of interest.

\section{References}

1. Fletcher, J.T.; Gaze, R.H. Mushroom Pests and Disease Control; Manson: London, UK, 2008; pp. 70-75.

2. Wong, W.C.; Preece, T.F. Sources of Verticillium fungicola on a commercial mushroom farm in England. Plant Pathol. 1987, 36, 577-582. [CrossRef] 
3. Berendsen, R.L.; Baars, J.J.P.; Kalkhove, S.I.C.; Lugones, L.G.; Wosten, H.A.B.; Bakker, A.H.M. Lecanicillum fungicola: Causal agent of dry bubble disease in white-button mushroom. Mol. Plant Pathol. 2010, 11, 585-595.

4. Shamshad, S.A.; Clift, A.D.; Mansfield, S. The effect of tibia morphology on vector competency of mushroom sciarid flies. J. Appl. Entomol. 2009, 133, 484-490. [CrossRef]

5. Grogan, H.; Gaze, R.H. Identification and Control of Dry Bubble Disease of Mushrooms; HDC Factsheet 09/08; Horticultural Development Company, East Malling: Kent, UK, 2008. Available online: http://hdl.handle.net/11019/1802 (accessed on 9 August 2021).

6. Pyck, N.; Grogan, H. MushTV Factsheet 04/15. Fungal Diseases of Mushrooms and Their Control. 2015. Available online: https:/ / www.teagasc.ie/publications /2015/fungal-diseases-of-mushrooms-and-their-control.php (accessed on 9 August 2021).

7. Piasecka, J.; Kavanagh, K.; Grogan, H. Detecting Bubble Trouble in Mushrooms. TResearch: Autumn 2012, 8 October 2012; pp. 26-27. Available online: https:/ / www.teagasc.ie/publications/2012/tresearch-autumn-2012.php (accessed on 9 August 2021). summarised from Piasecka, J.; Kavanagh, K.; Grogan, H. Detection of sources of Lecanicillium (Verticillium) fungicola on mushroom farms. In Mushroom Biology and Mushroom Products; Savoie, J.M., Foulonge-Oriol, M., Largeteau, M., Barroso, G., Eds.; INRA: Arcachon, France, 2011; pp. 484-489.

8. Boyce, J.M.; Pittet, D. Guideline for hand hygiene in health care settings: Recommendations of the Healthcare Infection Control Practices Advisory Committee and the HICPAC/SHEA/APIC/IDSA Hand Hygiene Task Force. Infect. Control Hosp. Epidemiol. 2002, 23, S3-S40. [CrossRef]

9. Grayson, M.L.; Melvani, S.; Druce, J.; Barr, I.G.; Ballard, S.A.; Johnson, P.D.R.; Mastorakos, T.; Birch, C. Efficacy of soap and water and alcohol based hand rub preparations against live H1N1 influenza virus on the hands of human volunteers. Clin. Infect. Dis. 2009, 48, 285-291. [CrossRef] [PubMed]

10. Jabbar, U.; Leischner, J.; Kasper, D.; Gerber, R.; Sambol, S.P.; Parada, J.P.; Johnson, S.; Gerding, D.N. Effectiveness of alcohol based hand rubs for removal of Clostridium difficile spores from hands. Infect. Control Hosp. Epidemiol. 2010, 31, 565-570. [CrossRef]

11. Singh, P.; Potlia, I.; Malhotra, S.; Dubey, H.; Chauhan, H. Hand Sanitizer an Alternative to Hand Washing-A Review of Literature. J. Adv. Oral Res. 2020, 11, 137-142. [CrossRef]

12. Leslie, R.A.; Zhou, S.S.; Macinga, D.R. Inactivation of SARS-CoV-2 by commercially available alcohol-based hand sanitizers. Am. J. Infect. Control 2021, 49, 401-402. [CrossRef] [PubMed]

13. Fendler, E.; Groziak, P. Efficacy of alcohol based sanitizers against fungi and viruses. Infect. Control Hosp. Epidemiol. 2002, 23, 61-62. [CrossRef] [PubMed]

14. World Health Organisation. Consensus recommendations. In WHO Guidelines on Hand Hygiene in Health Care; WHO Press: Geneva, Switzerland, 2009; pp. 151-156.

15. World Health Organisation. Surgical hand preparation: State of the art. In WHO Guidelines on Hand Hygiene in Health Care; WHO Press: Geneva, Switzerland, 2009; pp. 54-60.

16. Marchetti, M.G.; Kampf, G.; Finzi, G.; Salvatorelli, G. Evaluation of the bactericidal effect of five products for surgical hand disinfection according to prEN 12054 and prEN 12791. J. Hosp. Infect. 2003, 54, 63-67. [CrossRef]

17. World Health Organisation. Methods to evaluate the antimicrobial efficacy of handrub and hand wash agents and formulations for surgical hand preparation. In WHO Guidelines on Hand Hygiene in Health Care; WHO Press: Geneva, Switzerland, 2009; pp. 25-29.

18. Ogle, H.; Brown, J. Vector-borne inoculum. In Plant Pathogens and Plant Disease; Brown, J.F., Ogle, H.J., Eds.; Rockvale Publications: Berringer, NSW, Australia, 1997; pp. 231-241. 